\title{
Is the diagnostic radiological image an underutilised resource? Exploring the literature
}

\author{
William A. S. $\operatorname{Cox}^{1,3^{*}}$ De Penelope Cavenagh ${ }^{2}$ and Fernando Bello ${ }^{3}$
}

\begin{abstract}
The number of diagnostic imaging examinations being undertaken in the UK is rising. Due to the expensive nature of producing these examinations and the risks associated with exposing living tissue to the ionising radiation used by many of the imaging techniques, this growth comes with both a financial and a human cost. In a time of limited resources, it is important that we are able to maximise the benefits which we extract from these resources. Therefore, a broad search of the current literature was undertaken to assess our current understanding of the nature of benefit available from diagnostic radiological images.

Two broad categories of benefit were identified: primary benefit $(n=470)$ and secondary benefit $(n=49)$. Primary benefits are those which are related to the justification for undertaking the imaging, e.g., abnormality detection, to assist in diagnosis or staging, or acting as an aid to clinical decision making, or intervention. Secondary benefits are those that are not related to the justification for imaging, e.g., to promote patient engagement and understanding or to facilitate communication.

Existing work considering primary benefits is comprehensive. Secondary benefit, however, is less well recognised and may not be reliably realised. Use of the image to realise these benefits has far-reaching potential. Particularly, there may be underexplored benefits which access to the images may provide to patients. This represents a gap in existing research which should be addressed.
\end{abstract}

Keywords: Imaging, Diagnostic, Health benefits, Education, Patient, Communication, Behavior

\section{Key points}

- The number of diagnostic radiological images being acquired is growing; this process involves both a financial and a human cost

- This work assesses existing understanding of benefits available from these images

- Primary benefits, e.g., diagnosis, intervention and guidance, are comprehensively understood

- Secondary benefits, e.g., communication facilitation, could be explored further

\footnotetext{
* Correspondence: william.cox@port.ac.uk

'University of Portsmouth, James Watson West, 2 King Richard 1st Road, Portsmouth PO1 2FR, UK

${ }^{3}$ Imperial College London, London, UK

Full list of author information is available at the end of the article
}

\section{Introduction}

The number of diagnostic imaging examinations being undertaken in the UK is rising. 2016 alone saw growth of $2.1 \%$ [1]. Due to the expensive nature of producing these examinations [2] and the risks associated with exposing living tissue to the ionising radiation used by many of the imaging techniques, this growth comes with both a financial and a human cost.

Legislation dictates that each of the 40,654,715 examinations undertaken in 2016 was performed on the basis of a risk-benefit analysis [3]. Traditionally, expected benefits include the provision of abnormality detection, e.g., is there evidence of a fracture which will need treatment, or as an aid to clinical decision making, e.g., what type of fracture is present.

However, previous research has indicated that there are additional benefits available from these images [4]. 
Particularly, there may be underexplored benefits which access to the images may provide to patients.

It is important that we are able to maximise the benefits which we extract from these resources. According to benefits management theory, identification and structuring of benefits is the first stage in their realisation [5]. Moreover, it is important to establish whether there is a genuine imbalance in the literature with fewer studies pertaining to these additional benefits.

Thus, the questions for this review were:

1. What is the benefit of diagnostic radiological images?

2. To whom does the benefit accrue?

\section{Methodology}

A structured narrative approach was chosen due to the potentially qualitative nature of the topic precluding the use of a systematic review [6]. This approach can promote reliability, trustworthiness and dependability, while minimising bias and error [6].

\section{Search strategy}

Search terms were generated in alignment with the SPIDER (Sample, Phenomena of Interest, Design, Evaluation, Research type) tool. The SPIDER tool was selected as it was considered amongst a range of tools to be more effective in identifying qualitative and mixed methods studies. [7] This was important as this study was concerned with a range of benefits including those which are not medical but which are germane to this investigation.

This tool is designed to facilitate brainstorming of search terms and should 'contribute to a more systematic process to qualitative evidence synthesis, improving researcher confidence that all relevant articles have been sought in the search process' [8]. This review sought to investigate the potential benefits from imaging in the broad sense and was not primarily intended to address the potential benefits from specific modalities. The number of terms employed was restricted to those which arose through application of the SPIDER tool (Table 1) and were as below:

\section{Data sources}

In completing this review, the following databases were interrogated:

- CINAHL

- Cochrane library

- ProQuest

- PubMed

- Science Direct

\section{Screening}

Literature returned were screened for inclusion in alignment with the Preferred Reporting Items for Systematic Reviews and Meta-Analyses (PRISMA) guidelines [9] (Figs. 1 and 2). Although not a systematic review, the format provided by this validated instrument helped to shape the design of the review.

Table 1 SPIDER search terms and rationale

\begin{tabular}{|l|l|l|}
\hline SPIDER tool element & Search terms & Rationale \\
\hline Sample & $\begin{array}{l}\text { Ima* NOT imagina* NOT } \\
\text { imagine* NOT imagini* }\end{array}$ & $\begin{array}{l}\text { To include studies concerned } \\
\text { with physical images } \\
\text { To exclude studies considering } \\
\text { non-physical constructs e.g. } \\
\text { self-image, imagination }\end{array}$ \\
\hline Phenomenon of Interest & $\begin{array}{l}\text { Diagnostic OR medical OR } \\
\text { radiologic* OR radiograph* }\end{array}$ & $\begin{array}{l}\text { To include studies concerned } \\
\text { with diagnostic radiological } \\
\text { images } \\
\text { To exclude other imaging e.g. } \\
\text { medical photography }\end{array}$ \\
\hline Design & Any & $\begin{array}{l}\text { To avoid exclusion of relevant } \\
\text { studies based on design }\end{array}$ \\
\hline Evaluation & Role* OR valu* OR benefi* & $\begin{array}{l}\text { To include studies concerned } \\
\text { with the utility of images }\end{array}$ \\
\hline Research type & Qualitative OR mixed methods & $\begin{array}{l}\text { To promote the inclusion of } \\
\text { non-medical benefit types }\end{array}$ \\
\hline
\end{tabular}




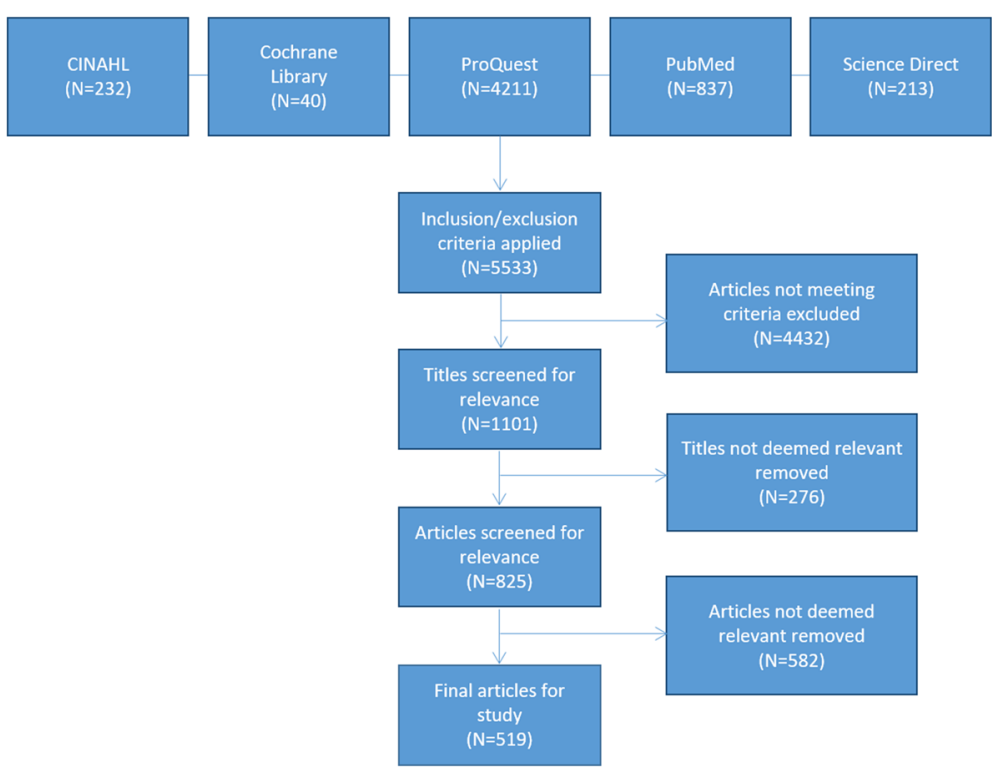

Fig. 1 Adapted PRISMA diagram

\section{Inclusion criteria}

Articles to be included were limited to those which concerned human imaging subjects, written in English and were published subject to peer-review within the last 10 years.

\section{Exclusion criteria}

Literature were excluded on the basis of relevance (concerned with metaphysical image constructs such as 'self-image') and scope (concerned with optical or cellular imaging).

\section{Results}

A total of 5533 articles were returned. These articles were distributed across the databases as below:

- CINAHL-232

- Cochrane library-40

- ProQuest-4211

- PubMed-837

- Science Direct-213

Following application of the screening criteria, 519 articles were selected for analysis.

A meta-analysis of this data was deemed to be inappropriate as the explorative nature of the review entailed inclusion of diverse study designs, with differing outcome measures.

Articles were allocated themes extracted through familiarisation with the contents and based on the types of benefits described or addressed within the articles.
Following allocation of individual themes to the literature, two broad categories of benefit type were identified:

- Primary benefits $(n=470)$

- Secondary benefits $(n=49)$

\section{Primary benefits}

The majority of literature returned $(n=470)$ was categorised as concerning primary benefits (see Table 2). Primary benefits are benefits extracted from the image which align with the rationale for its acquisition. Such benefits tend to fit with a traditional understanding of image value and may be further sub-categorised in alignment with the patient pathway temporally as follows:

- At the detection phase; for abnormality discovery

- At the diagnostic phase; for condition identification and further assessment

- At the management phase; for decision making, intervention or follow-up

An in-depth analysis of all of the facets of clinical benefit in images is beyond the scope of this article. However, the types of benefits which contributed to each phase are briefly described below:

\section{Detection phase}

This phase includes a range of benefits covering not only detection of abnormalities, for example, the clinical utility of 99mTc-labelled ubiquicidin 29-41 antimicrobial peptide for detecting mediastinitis following cardiac surgery [10] or 


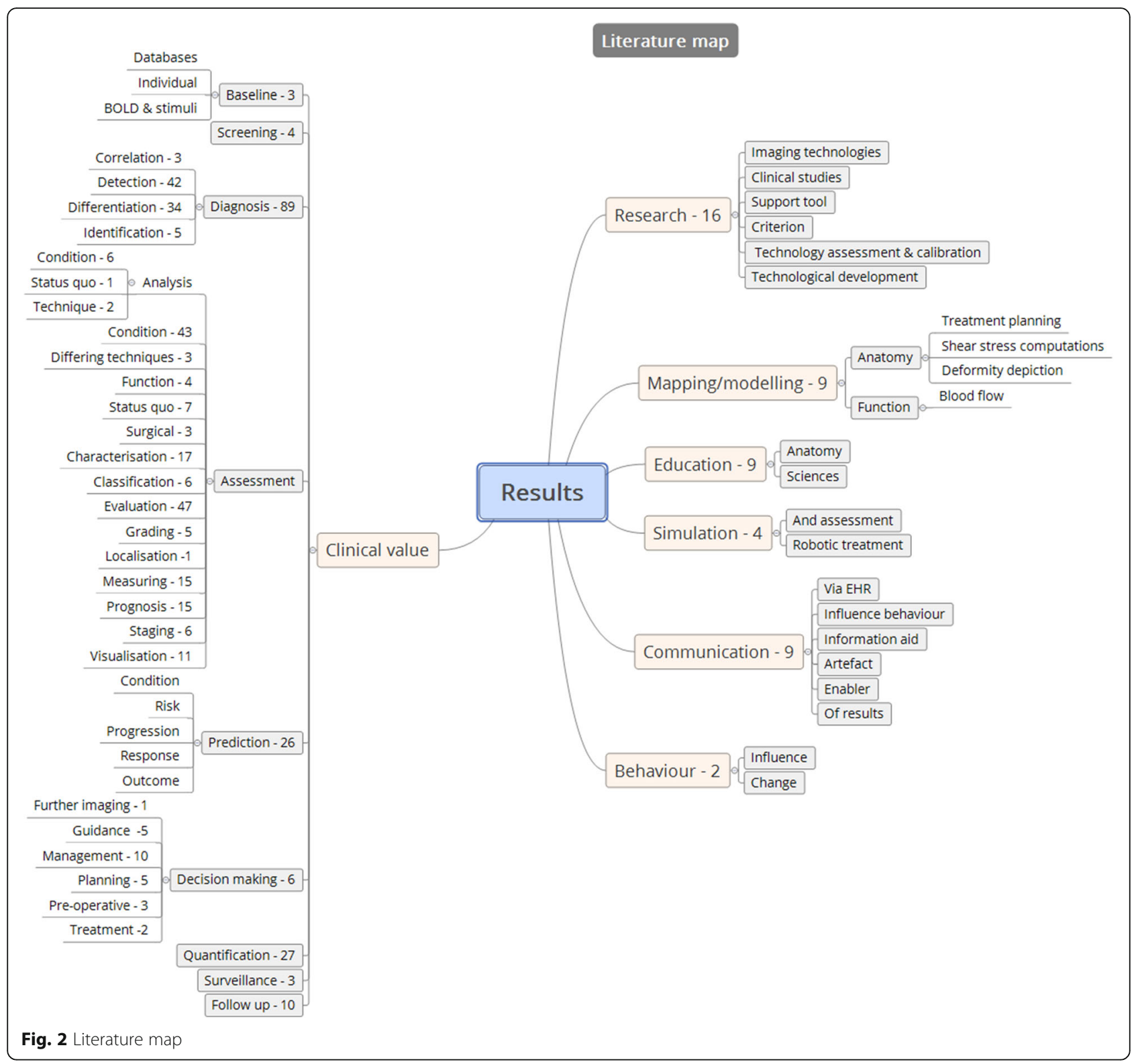

the assessment of accuracy of dual-time-point 18F-FDG PET, but, further, the contribution of imaging to the ruling out of abnormalities, as well as its use as a screening tool in both public health initiatives such as the breast screening programme [11], and private health M.O.T. packages [12].

\section{Diagnostic phase}

This phase deals with benefits which the image may contribute once the presence of an abnormality has been confirmed. Such benefits include the contribution of the image to the formulation of a diagnosis [13, 14], the measurement [15-17] or classification [18-20] of the abnormality and the contribution of imaging information to disease staging [21-23].

\section{Management phase}

This phase is concerned with how the patient is subsequently managed. Images have a recognised role in supporting interventional procedures and other healthcarerelated activities either pre-, peri-, or post-intervention. Pre-interventional benefits include contribution to surgical planning [24, 25] and decision making [26, 27], peri-interventional benefits are those concerned with image guided procedures such as biopsies or surgery $[28,29]$, and post-interventional benefits include the contribution of images to follow-up and monitoring processes [30,31].

\section{Secondary benefits}

Beyond the primary benefit types described above, there are various secondary benefit types recognised within 
Table 2 An overview of study types and contents and the primary benefit categories

\begin{tabular}{|c|c|c|c|c|c|c|}
\hline Study & Benefit category & Benefit type & Specific Benefit & Study gype & Method & Sample size \\
\hline Vallejo et al.9 & Primary & Diagnosis & Diagnosis of mediastinitis after cardiac surgery & Quantitative & $\begin{array}{l}\text { Comparison of qualitative image } \\
\text { analysis with bacterial culture }\end{array}$ & 13 participants \\
\hline Destounis et al.10 & Primary & Detection & Detection of breast cancer lesions & Quantitative & $\begin{array}{l}\text { Comparison of detection rates by } \\
\text { varying cohort characteristics, e. . age }\end{array}$ & 793827 participants \\
\hline Grueneisen et al.12 & Primary & Staging & $\begin{array}{l}\text { Whole body staging of women with primarry or } \\
\text { receurring malignancies of the pelvis }\end{array}$ & Quantitative & $\begin{array}{l}\text { Comperison of sensitivity, specificity, } \\
\text { accuract, } \mathrm{PPV} \text { and NPV for } 18 F-\text {-FDG } \\
\text { PET/MR imaging protocol with/without } \\
\text { diffusion-weighted imaging (DWI) }\end{array}$ & 48 participants \\
\hline Campuzano Marin et al. az & Primery & Diegnosis & $\begin{array}{l}\text { Contribution to the digenosis of } A C L \text { failure and } \\
\text { identification of concomitant injuries }\end{array}$ & Quantitative & $\begin{array}{l}\text { Statistical comparison of variables } \\
\text { impacting on diagnosis }\end{array}$ & 101 cases \\
\hline Kantarci et al. 14 & Primary & Detection & Detection of small labral tears in the hip & Quantitative & $\begin{array}{l}\text { Comparison of tears identified on MR } \\
\text { with hip arthroscopy }\end{array}$ & 48 participants \\
\hline Lackner et al. 15 & Primary & Measurement & $\begin{array}{l}\text { Measurement of flow in normal and obstructed } \\
\text { vessels }\end{array}$ & Quantitative & $\begin{array}{l}\text { Use of mathematical algorithm to } \\
\text { calculate temporal density changes in } \\
\text { cross-section examined }\end{array}$ & Simulation based \\
\hline Margossian et al. ${ }^{16}$ & Primery & Measurement & $\begin{array}{l}\text { Measurement of functional single ventricular } \\
\text { volumes, mass and ejection fractions }\end{array}$ & Quontitotive & $\begin{array}{l}\text { Comporison of messurements made } \\
\text { with echocard diography and MRI }\end{array}$ & 150 studies \\
\hline Abdulkadir et al.17 & Primary & Classification & Alzheimer's disease classsification & Quantitative & $\begin{array}{l}\text { Application of machine learning } \\
\text { methods to MRI data }\end{array}$ & 518 MRI sessions \\
\hline Rodriguez Guttierrez et al.1.". & Primary & Classification & $\begin{array}{l}\text { Classification of paediatric posterior fossa } \\
\text { tumours }\end{array}$ & Quantitative & $\begin{array}{l}\text { Retrospective assessment of features } \\
\text { to derive a tumour subtype classifier }\end{array}$ & 40 participants \\
\hline Koyama et al. ${ }^{19}$ & Primary & Classification & $\begin{array}{l}\text { Detection and subtrpe classification of } \\
\text { pulmonary adenocarcinomas }\end{array}$ & Quantitative & $\begin{array}{l}\text { Comparison of detection rates and } \\
\text { differentiation capabilities assessed } \\
\text { between DWI \& STTR and against ROC- } \\
\text { based positive tests }\end{array}$ & 32 participants \\
\hline Crawford et al. 20 & Primary & Staging & $\begin{array}{l}\text { Pre-operative staging in patients with primary } \\
\text { colorectal cancer }\end{array}$ & Quantitative & $\begin{array}{l}\text { Systematic literature review of studies } \\
\text { assessing value of PET-CT in staging }\end{array}$ & $n / a$ \\
\hline Michielsen et al.." & Primary & Staging & $\begin{array}{l}\text { Characterisation and assessment of the spread } \\
\text { and operability of suspectede ovarian cancer }\end{array}$ & Quantitative & $\begin{array}{l}\text { Imaging findings compared with } \\
\text { nistopathology or image guided } \\
\text { biopsies }\end{array}$ & 32 participants \\
\hline Ramezani-Badr et al.22 & Primary & Decision making & $\begin{array}{l}\text { Contribution to reasoning strategies and } \\
\text { criteria for clinical decision making }\end{array}$ & Qualitative & $\begin{array}{l}\text { Hypothesis testing through imaging } \\
\text { studies }\end{array}$ & 14 participants \\
\hline Agarwal et al.,23 & Primary & Decision making & $\begin{array}{l}\text { Contribution to clinical decision making } \\
\text { regarding thrombolysis }\end{array}$ & Qualitative & $\begin{array}{l}\text { Retrospective image evaluation and } \\
\text { statistical testing for inter-rater } \\
\text { agreement }\end{array}$ & 40 studies \\
\hline Tognolini et al.24 & Primary & Decision making & $\begin{array}{l}\text { Preoperative assessment for risk factors in } \\
\text { Patients prior to undergoing bariatric surgery }\end{array}$ & Quantitative & $\begin{array}{l}\text { Imaging findings compared with Cas } \\
\text { and cardiovescular (IV) risk } \\
\text { stratification blood tests }\end{array}$ & 30 participants \\
\hline Lenza et al.25 & Primary & Decision making & Preoperative assessment of rotator cuff tears & Quantitative & $\begin{array}{l}\text { Systematic literature review of studies } \\
\text { assessing ciagnostic accuracy imaging } \\
\text { tests for rotator cuff tears }\end{array}$ & 20 studies \\
\hline Carbone et al. ${ }^{36}$ & Primary & Management & $\begin{array}{l}\text { Contribution to the management of detected } \\
\text { rodulus and potential importance for } \\
\text { contouring radiotherapy treatment volumes }\end{array}$ & Mixed methods & $\begin{array}{l}\text { Evaluation of diffusion-weighted MR } \\
\text { inaging (DWI) of nnown nodular } \\
\text { lesions with assessment for sensitivity, } \\
\text { specificity, accuracy, NPV and PPV }\end{array}$ & 27 participants \\
\hline Chaver-Tapia Noberto et al.27 & Primary & Guidance & $\begin{array}{l}\text { Assessment of the effects of image-guided } \\
\text { percutaneous procedure }\end{array}$ & Quantitative & $\begin{array}{l}\text { Systematic iterature review of studies } \\
\text { comparing image-guided percutaneous } \\
\text { procedure vs atternative technique }\end{array}$ & 7 studies \\
\hline Tian et a..28 & Primary & Peri-operative guidance & Improved accuracy of pedicle screw placement & Quantitative & $\begin{array}{l}\text { Placement utilising 3-dimensional } \\
\text { fluoroscopic methoss assessed for axial } \\
\text { rotation vs. traditional placement } \\
\text { methods }\end{array}$ & 160 pedicle screws \\
\hline Uchiyama et al. ${ }^{29}$ & Primary & Monitoring & 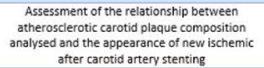 & Mixed methods & $\begin{array}{l}\text { Quantitative and qualitative analysis of } \\
\text { plaque characteristiss utilising MDCT } \\
\text { and DWI }\end{array}$ & 19 studies \\
\hline
\end{tabular}

the literature (see Table 3). These are the types of benefit which are not necessarily related to the purposes for which the images were originally intended. This benefit is less well recognised and often less tangible. The literature describes these forms of benefit infrequently and seldom directly. They may be categorised as:

- Educational benefit

- Relational benefit

- Technological benefit

\section{Educational benefit}

Images have traditionally been used in the teaching of anatomy to health students. However, the breadth of areas where images can contribute benefit in the educational sense is gradually increasing [32]. This expansion of understanding has implications for our thinking around the benefit which images may contribute. For example, the benefit which radiological images contribute to the teaching of anatomy and physiological processes is recognised within the literature [33]. The use of images in this sense promotes understanding through providing context [34]. Beyond their benefit in this reference oriented sense, images, or the production of images, can be used directly in anatomical instruction. Ultrasound (U/S), for example, when used as a tool for teaching abdominal anatomy, was valued by students as a means for reinforcing their existing academic knowledge through hands-on clinical contextualisation [35].
Further, the growing availability of 3D imaging datasets allows students to visualise time series imaging studies displaying motion of either organs, e.g., the beating heart [32], or substances. Thus, images can be used to demonstrate both structural and process-based/functional information in both health and disease. Baghdady et al. [34] found that incorporation of the image in this sense had a significant effect on learning $(p=0.01)$. Groups who were taught basic science with links between disease pathophysiology and radiologic features integrated with imaging outperformed groups who were delivered segregated basic sciences in diagnostic accuracy. While this is a single study, and there is a need for further work, this does support the suggestion that a role exists for radiological images in teaching in this area.

\section{Relational benefit}

Building on and extending educational benefit is relational benefit. Relational benefit in this context refers to the potential for images to contribute to the relationships between stakeholders. The contribution of relational benefit by diagnostic images may be categorised as promoting the following:

- Communication

- Engagement

Communication The image has been indirectly recognised for its benefit as an artefact of communication, 
Table 3 An overview of study types and contents and the secondary benefit categories

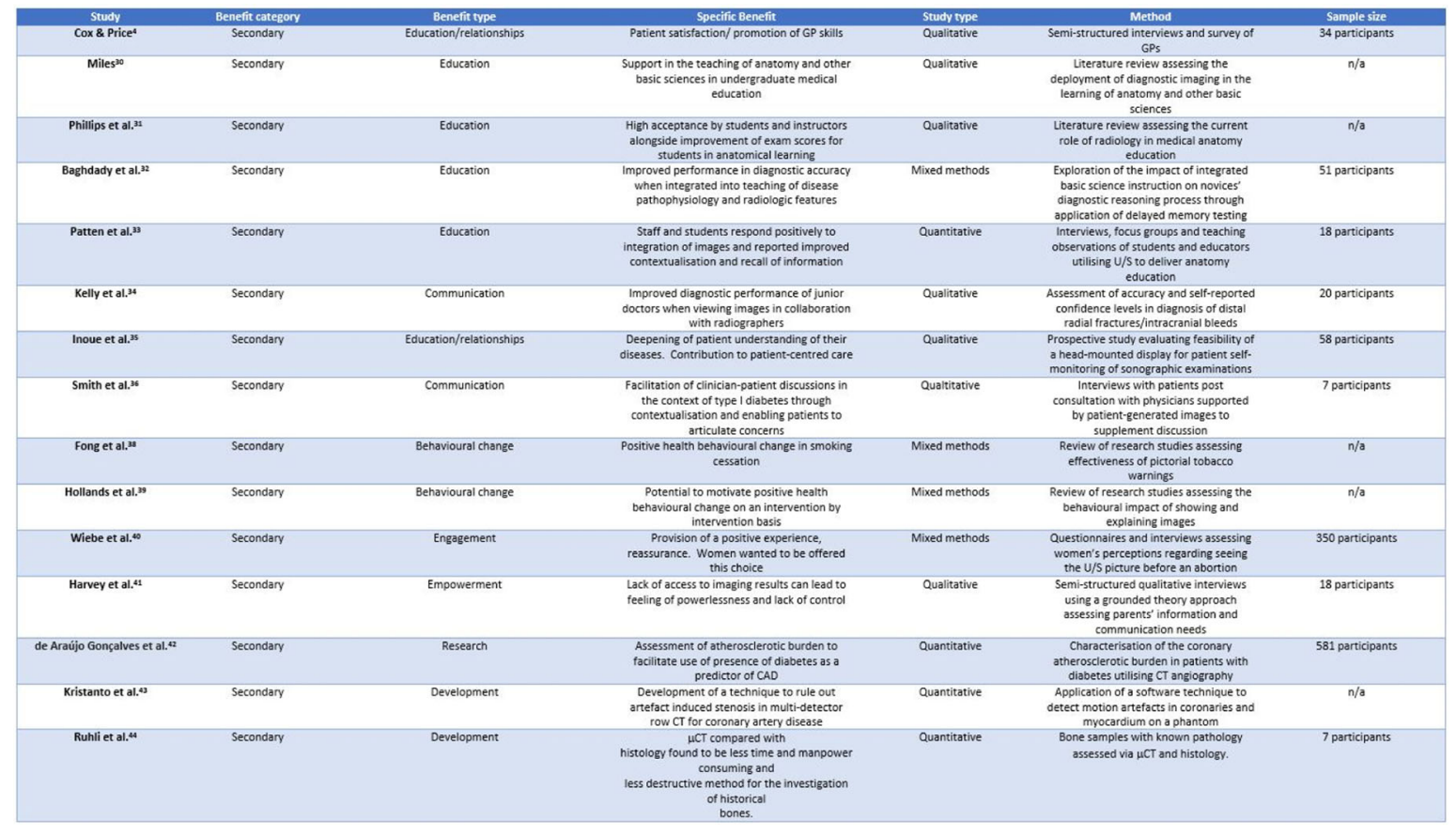

providing a focal point for discussion both between clinicians [36] and between clinicians and their patients [37]. Shared interpretation of radiographs by clinicians in the accident and emergency (A\&E) environment resulted in area under the curve (AUC) scores for interpretation improving significantly for both conventional and CT images [36]. Additionally, GPs perceive images as useful for communicating with, and providing reassurance to, patients [35]. Images have also been shown to facilitate clinician-patient discussion regarding patients' condition [38] and have the potential to allow patients to articulate concerns and ask questions. This has been argued to result in decreased patient anxiety, increased patient confidence in services, and promoting the development of a partnership-based approach to their care [37].

Engagement Engagement is another avenue via which relational benefit may be demonstrated. Engagement in this context may be defined as the contribution that diagnostic radiological images make to the enablement of stakeholders in the processes surrounding the healthcare encounter. These benefits may accrue to any stakeholder, but are particularly pertinent to patients and other non-clinical stakeholders. This engagement may be evidenced through the promotion of behavioural change, patient empowerment and satisfaction.

The role of visual stimuli in influencing human behaviour has been widely explored in several academic fields, including marketing and preventative medicine [39]. A pertinent example is the significant impact on smoking cessation realised through use of vivid imagery on cigarette packages [40]. A Cochrane review from 2010 directly assessed the impact of visual feedback of individuals' medical imaging results on changing their health behaviours. The review included two trials utilising U/S images and two trials utilising CT images. The trials assessed whether the use of images in the feedback of test results could influence subject behaviour against various outcomes [41]. While this review does demonstrate some recognition of the potential for images to promote behavioural change, the findings were not conclusive. The authors noted that the volume of available evidence was limited and further work is required in this area [41].

Beyond behavioural change, images promote the empowerment and satisfaction of non-clinical stakeholders. In one study, women volunteered a desire to see pre-abortion U/S images of their foetuses [42]. While this access did not measurably influence the decision to undergo the procedure, the women did note that access to the images helped them to feel empowered and in control of the situation [42]. Empowerment was also cited as a factor in the importance of access to images by parents of children in the neonatal unit (NNU) in a study assessing levels of information and communication provision from care providers regarding their children [43]. Patients report that, on occasion, they do not feel 
informed about the results of diagnostic tests including diagnostic imaging leading to feelings of powerlessness and lack of control [43].

\section{Technological benefit}

Finally, the literature describes benefit which may be extracted from images in a technological sense. Beyond a well-developed tradition of using imaging in clinical research, for example, utilising images as a predictor of pathology [44]; contributing to the development, refinement and calibration of existing technologies [45]; or providing a basis upon which to compare and refine existing techniques [46], images may contribute to the development of novel technologies such as the production of models of organs through $3 \mathrm{~d}$ printing based on data acquired from diagnostic radiological imaging procedures. Recently, companies including M3dia Studio [47] and 3dprinting.com [48] have been producing such models. These in turn may be utilised to inform new or improved imaging techniques in order to answer specific questions $[47,48]$. Techniques such as $3 \mathrm{~d}$ reconstruction have previously played a role in surgical planning, but, if internal architecture can be copied and reproduced through 3D printing, the benefit of imaging for surgeons to practice in specific cases is all the more powerful.

\section{Discussion}

The majority of the literature returned was concerned with primary benefit forms $(n=470$ of $n=519)$. This is overwhelmingly clinical in nature and was recognised as being comprised of tangible benefits, which are clinically orientated and tend to be measurable. These benefits tend to accrue directly to clinicians.

Secondary benefit was less well developed. This was defined as being comprised of benefits which were not intended for extraction at the point of image acquisition and tended to be comprised of less tangible benefits, which are difficult to measure. Secondary benefits, however, offer several novel opportunities under three broad benefit subtypes: educational benefit, where images were noted as having a positive impact on recall and understanding; relational benefit, where images were recorded as promoting education and engagement; and technological benefit, where images contributed to the development of both novel technologies and techniques.

Technological benefit is likely to be an area of growing importance with developments in Artificial Intelligence (AI) having the potential to impact on radiology in a number of key areas including automated detection. Many of these capabilities benefit from the increasing availability of datasets to improve their reliability and, therefore, their clinical utility both in improving the diagnostic value of the images themselves and in potentially contributing to alleviating pressures rooted in workforce shortages.

Additionally, secondary benefits may accrue directly to a wider stakeholder group. There is little consideration within the existing literature of how patients, for example, may directly access benefits from their own images. Indeed, no work directly asks what stakeholders actually perceive as the benefit of diagnostic radiological images. This may be as a function of stakeholders lacking avenues for accessing such benefit. However, access to patient portals is increasing and, therefore, an understanding of stakeholder perceptions of potential benefit from diagnostic radiological images, particularly pertaining to stakeholders external to the clinical environment, is becoming increasingly pertinent. Furthermore, there are important questions to be answered surrounding how such access might be managed in order to enable stakeholders to realise potential benefits while mitigating any inherent risks.

\section{Limitations}

While the search terms and data sources for this review were deliberately broad, there remains a risk that relevant articles may have been missed. While this review exclusively utilised the SPIDER tool in identifying literature, it is possible that using additional search tools may have increased the number of articles identified. Furthermore, no literature explicitly asks the question of what benefits are available from diagnostic radiological images. As such, the benefits listed were identified through a categorisation process which may reflect the bias of the reviewers.

In considering secondary benefits, it is important to note that, while potentially important, there should be no confusion as to the role these benefits play in the justification of imaging. Secondary benefits can only be considered as being supplementary in nature and imaging should not be undertaken based on the potential to realise these benefits.

\section{Conclusion}

The existing work which addresses primary benefit in images is comprehensive. However, beyond the primary benefit of images, there are a number of secondary, or recycled, benefits available. For example, the literature indicates the potential to use the diagnostic radiological image to promote education or to enhance and promote communication and engagement. Such usage has wide ranging potential benefits. The use of the image as an artefact for interpersonal communication, for example, may prospectively act as an information aide or adjunct, assist with conveying findings, provide reassurance and help to deliver personalised care. Additionally, there is some evidence that diagnostic radiological images have benefit as a tool to influence health behaviour. 
Furthermore, a Cochrane review conducted on this subject explicitly calls for further work in this area [41].

Despite the above, however, the potential of the image for realising a secondary benefit remains largely underexplored, an incidental by-product of the imaging process. This is a gap which should be addressed through further research.

\author{
Abbreviations \\ A\&E: Accident and emergency; AUC: Area under the curve; NNU: Neonatal \\ unit; PRISMA: Preferred Reporting Items for Systematic Reviews and Meta- \\ Analyses; SPIDER: Sample, Phenomena of Interest, Design, Evaluation; U/ \\ S: Ultrasound
}

\section{Funding}

The authors state that this work has not received any funding.

\section{Guarantor}

The scientific guarantor of this publication is William Cox.

\section{Authors' contributions}

WC was involved with the acquisition of the data and writing the manuscript. FB and PC assisted in writing the manuscript, provided critique of the content and were involved with the review of the manuscript. All authors read and approved the final manuscript.

\section{Ethics approval and consent to participate}

Not applicable.

\section{Competing interests}

The authors declare that they have no competing interests.

\section{Publisher's Note}

Springer Nature remains neutral with regard to jurisdictional claims in published maps and institutional affiliations.

\section{Author details}

'University of Portsmouth, James Watson West, 2 King Richard 1st Road, Portsmouth PO1 2FR, UK. ${ }^{2}$ University of Suffolk, Ipswich, UK. ${ }^{3}$ Imperial College London, London, UK.

Received: 13 August 2018 Accepted: 8 November 2018

Published online: 06 February 2019

\section{References}

1. National Health Service England (2016) Diagnostic imaging dataset annual statistical release 2015/16. Available at: https://www.england.nhs.uk/ statistics/wp-content/uploads/sites/2/2015/08/Annual-Statistical-Release2015-16-DID-PDF-1.5MB.pdf Accessed 26 May 2017

2. Wanless, D. (2007). Our future health secured? A review of NHS funding and performance. London, The King's Fund [electronic]. Available from: http:// www.kingsfund.org.uk/publications/our-future-health-secured [Accessed 29 May 2016]

3. The lonising Radiation (Medical Exposure) Regulations 2017 (SI 2017/1322). (2017). HMSO, London

4. Cox WAS, Price R (2014) What general practitioners require of diagnostic imaging departments: A case study. Radiography 20(2):131-136

5. Glynne P (2007) Benefits management-changing the focus of delivery. Association for Progress Management Yearbook 2006, vol 7, pp 45-49

6. Aveyard H (2010) Doing a literature review in health and social care: a practical guide, 2nd edn. OUP, McGraw-hill

7. Methley AM, Campbell S, Chew-Graham C, McNally R, Cheraghi-Sohi S (2014) PICO, PICOS and SPIDER: a comparison study of specificity and sensitivity in three search tools for qualitative systematic reviews. BMC Health Serv Res 14:579

8. Cooke A, Smith D, Booth A (2003) Beyond PICO: the SPIDER tool for qualitative evidence synthesis. Qual Health Res 22(10):1435-1443
9. Moher D, Liberati A, Tetzlaff J, Altman DG (2010) Preferred Reporting Items for Systematic Reviews and Meta-Analyses: the PRISMA statement. Int I Surg 8(5):336-341

10. Vallejo E, Martinez I, Tejero A et al (2008) Clinical utility of 99mTc-labeled ubiquicidin 29-41 antimicrobial peptide for the scintigraphic detection of mediastinitis after cardiac surgery. Arch Med Res 39(8):768-774

11. Destounis SV, Arieno AL, Morgan RC et al (2014) Comparison of breast cancers diagnosed in screening patients in their 40s with and without family history of breast cancer in a community outpatient facility. AJR Am J Roentgenol 202(4):928-932

12. Bupa.co.uk (2019) Colon health check. Available at https://www.bupa.co.uk/ health/health-assessments/colon-health. Accessed 29 Jan 2019.

13. Grueneisen J, Schaarschmidt BM, Beiderwellen K et al (2014) Diagnostic value of diffusion-weighted imaging in simultaneous 18F-FDG PET/MR imaging for whole-body staging of women with pelvic malignancies. J Nucl Med 55(12):1930-1935

14. Campuzano Marín MA, Gómez-Castresana Bachiller F (2010) Anterior cruciate ligament failure: diagnostic value of the clinical examination and magnetic resonance imaging. Rev Esp Cir Ortop Traumatol (English Edition) 54(6):363-371

15. Kantarci F, Ozpeynirci Y, Unlu M et al (2012) Cross-sectional area of the labrum: role in the diagnosis of anterior acetabular labral tears. Eur Radiol 22(6):1350-1356

16. Lackner K, Bovenschulte H, Stützer H, Just T, Al-Hassani H, Krug B (2011) In vitro measurements of flow using multislice computed tomography (MSCT). Int J Cardiovasc Imaging 27(6):795-804

17. Margossian R, Schwartz ML, Prakash A et al (2009) Comparison of echocardiographic and cardiac magnetic resonance imaging measurements of functional single ventricular volumes, mass, and ejection fraction (from the pediatric heart network Fontan cross-sectional study). Am J Cardiol 104(3):419-428

18. Abdulkadir A, Mortamet B, Vemuri P, Jack CR Jr, Krueger G, Klöppel S (2011) Effects of hardware heterogeneity on the performance of SVM Alzheimer's disease classifier. Neuroimage 58(3):785-792

19. Rodriguez Gutierrez D, Awwad A, Meijer L et al (2014) Metrics and textural features of MRI diffusion to improve classification of pediatric posterior fossa tumors. AJNR Am J Neuroradiol 35(5):1009-1015

20. Koyama H, Ohno Y, Aoyama N et al (2010) Comparison of STIR turbo SE imaging and diffusion-weighted imaging of the lung: capability for detection and subtype classification of pulmonary adenocarcinomas. Eur Radiol 20(4):790-800

21. Crawford F, Mclntosh H, Dozier M et al (2012) FDG PET-CT imaging for pre operative staging in patients with colorectal cancer. In: Anonymous Cochrane Database of Systematic Reviews

22. Sommer G, Schaefer AO, Baumann T, Ludwig UA, Fautz HP (2008) Sliding multislice MRI for abdominal staging of patients with pelvic malignancies: a pilot study. J Magn Reson Imaging 27(3):666-672

23. Michielsen K, Vergote I, Op De Beeck K et al (2014) Whole-body MRI with diffusion-weighted sequence for staging of patients with suspected ovarian cancer: a clinical feasibility study in comparison to CT and FDG-PET/CT. Eur Radiol 24(4):889-901

24. Ramezani-Badr F, Nasrabadi AN, Yekta ZP, Taleghani F (2009) Strategies and criteria for clinical decision making in critical care nurses: a qualitative study. J Nurs Scholarsh 41(4):351-358

25. Agarwal S, Jones PS, Alawneh JA et al (2011) Does perfusion computed tomography facilitate clinical decision making for thrombolysis in unselected acute patients with suspected ischaemic stroke? Cerebrovasc Dis 32(3):227-233

26. Tognolini A, Arellano CS, Marfori W et al (2013) Cardiac dual-source CT for the preoperative assessment of patients undergoing bariatric surgery. Clin Radiol 68(3):e154-e163

27. Lenza M, Buchbinder R, Takwoingi Y, Johnston R, Hanchard N, Faloppa F (2013) Magnetic resonance imaging, magnetic resonance arthrography and ultrasonography for assessing rotator cuff tears in people with shoulder pain for whom surgery is being considered. In: Anonymous Cochrane Database of Systematic Reviews, In

28. Carbone SF, Pirtoli L, Ricci V et al (2014) Diffusion-weighted magnetic resonance diagnosis of local recurrences of prostate cancer after radical prostatectomy: preliminary evaluation on twenty-seven cases. Biomed Res Int 2014:780816

29. Chavez-Tapia NC, Hernandez-Calleros J, Tellez-Avila FI, Torre A, Uribe M (2009) Image-guided percutaneous procedure plus metronidazole versus metronidazole 
alone for uncomplicated amoebic liver abscess. In: Anonymous Cochrane Database of Systematic Reviews

30. Tian W, Lang Z (2010) Placement of pedicle screws using three-dimensional fluoroscopy-based navigation in lumbar vertebrae with axial rotation. Eur Spine J 19(11):1928-1935

31. Uchiyama N, Misaki K, Mohri M et al (2012) Association between carotid plaque composition assessed by multidetector computed tomography and cerebral embolism after carotid stenting. Neuroradiology 54(5):487-493

32. Miles KA (2005) Diagnostic imaging in undergraduate medical education: an expanding role. Clin Radiol. 60:742-745

33. Phillips AW, Smith SG, Straus CM (2013) The role of radiology in preclinical anatomy: a critical review of the past, present, and future. Acad Radiol 20(3): 297-304.e1

34. Baghdady MT, Carnahan H, Lam EW, Woods NN (2013) Integration of basic sciences and clinical sciences in oral radiology education for dental students. J Dent Educ 77(6):757-763

35. Patten D (2015) Using ultrasound to teach anatomy in the undergraduate medical curriculum: an evaluation of the experiences of tutors and medical students. Ultrasound 23(1):18-28

36. Kelly BS, Rainford LA, Gray J, McEntree MF (2012) Collaboration between radiological technologists (radiographers) and junior doctors during image interpretation improves the accuracy of diagnostic decisions. Radiography 18:90-95

37. Inoue M, Kihara K, Yoshida S et al (2015) A novel approach to patient selfmonitoring of sonographic examinations using a head-mounted display. J Ultrasound Med 34:29-35 0278-4297

38. Smith BK, Frost J, Albayrak M, Sudhakar R (2006) Facilitating narrative medical discussions of type 1 diabetes with computer visualizations and photography. Patient Educ Couns 64(1-3):313-321

39. Woolford SJ, Khan S, Barr KL, Clark SJ, Strecher VJ, Resnicow K (2012) A picture may be worth a thousand texts: obese adolescents' perspectives on a modified photovoice activity to aid weight loss. Child Obes 8(3):230-236

40. Fong GT, Hammond D, Hitchman SC (2009) The impact of pictures on the effectiveness of tobacco warnings. Bull World Health Organ 87:565-644

41. Hollands GJ, Hankins M, Marteau TM (2010) Visual feedback of individuals' medical imaging results for changing health behaviour, Cochrane Database Syst Rev 20:CD007434

42. Wiebe $E R$, Adams $L$ (2009) Women's perceptions about seeing the ultrasound picture before an abortion. Eur J Contracept Reprod Health Care 14(2):97-102

43. Harvey ME, Nongena P, Gonzalez-Cinca N, Edwards AD, Redshaw ME (2013) Parents' experiences of information and communication in the neonatal unit about brain imaging and neurological prognosis: a qualitative study. Acta Paediatr 102:360-365

44. de Araújo Gonçalves P, Garcia-Garcia HM, Carvalho MS et al (2013) Diabetes as an independent predictor of high atherosclerotic burden assessed by coronary computed tomography angiography: the coronary artery disease equivalent revisited. Int J Cardiovasc Imaging. 29(5):1105-1114

45. Kristanto W, van Ooijen PM, Dikkers R, Greuter MJ, Zijlstra F, Oudkerk M (2010) Quantitative image analysis for the detection of motion artefacts in coronary artery computed tomography. Int J Cardiovasc Imaging 26(1): 77-87. https://doi.org/10.1007/s10554-009-9502-x

46. Rühli FJ, Kuhn G, Evison R, Müller R, Schultz M (2007) Diagnostic value of micro$C T$ in comparison with histology in the qualitative assessment of historical human skull bone pathologies. Am J Phys Anthropol 133(4):1099-1111

47. M3dia Studio (2016) Homepage. Available at http://www.media-studio.co.uk accessed 12 Feb 2016

48. 3dPrinting.com (2016) Homepage. Available at http://www.3dprinting.com accessed 14 Feb 2016

\section{Submit your manuscript to a SpringerOpen ${ }^{\circ}$ journal and benefit from:}

- Convenient online submission

- Rigorous peer review

- Open access: articles freely available online

- High visibility within the field

- Retaining the copyright to your article

Submit your next manuscript at $\boldsymbol{\nabla}$ springeropen.com 